\title{
TONE COMPRESSION ALGORITHM FOR HIGH DYNAMIC RANGE MEDICAL IMAGES
}

\author{
I. A. Gracheva ${ }^{1, *}$, A. V. Kopylov ${ }^{1}$ \\ ${ }^{1}$ Tula State University, Tula, Russia - gia1509@mail.ru, andkopylov@gmail.com
}

KEY WORDS: Image Processing, Tone Mapping, HDR Medical Image, Probabilistic Gamma-normal Model.

\begin{abstract}
:
We propose here an HDR compression method for medical images based on a windowing operator, an adaptive tone mapping operator, and the probabilistic normal-gamma model. First, we use the windowing operator based on a structural fidelity measure for optimal visualization of the input HDR medical image. Then, we transform the windowed image to the logarithm domain and split it into base and detail layers with the help of the probabilistic normal-gamma model. Base and detail layers are used to make the tone map with help the adaptive tone mapping operator. Finally, the tone mapping result is the LDR image. The proposed method has comparable quality and low computation time compared to other tone mapping operators.
\end{abstract}

\section{INTRODUCTION}

Technological advances in medicine lead to complication of acquisition and diagnostic devices and, consequently, to increase the quality medical images. The technology of fusion images with different exposures to expand dynamic range and preserve the detailed information is widely used e.g. for X-ray (Skurowski, 2018) and Magnetic Resonance Imaging (Hung, 2013). Moreover, images stored according to the Digital Imaging and Communications in Medicine (DICOM) standard (Pianykh, 2008) typically have a precision of 12 to 16 bits per pixel that is higher than common Low Dynamic Range (LDR) images with precision 8 to 10 bits per pixel.

At the same time, modern displays have high contrast and luminance but cannot visualize images with High Dynamic Range (HDR). Therefore, tone mapping operators (TMO's) and windowing operators are needed to convert HDR to LDR images, which can be seen on common displays. Tone mapping operators aim at maintaining the overall contrast and brightness levels imitating images with a high dynamic range. The most important aspect of these operators is saving texture, contrast and brightness information of an image. The relative amount of information of the above-mentioned characteristics is one of the parameters used to measure the quality of the tone mapped image. Windowing operators map an intensity interval of interest linearly to the dynamic range of the display. Linear mapping is the most straightforward windowing operator but may not be the optimal mapping function in terms of structure preserving. An adaptive framework for finding the optimal windowing function for different medical images can help to solve this problem. Combination of windowing operators and TMO compression followed by windowing (CW) and windowing followed by compression (WC) gives better results (Athar, 2015).

In this paper, we propose the new HDR image compression method. The method is based on the combination of the windowing operator (Nikvand, 2014) and the TMO, along with base and detail layers technique (Durand, 2002) using the probabilistic normal-gamma model (Gracheva, 2015, Gracheva, 2017). The windowing operator is used for optimal visualization of medical images. It has an adaptive scheme based on structural fidelity measure, which can find an optimal windowing operator for different medical images. The probabilistic normal-gamma model of the hidden field performed well in image denoising, image haze removal, and the structure-transferring problem. The advantages of this model are strict mathematical formulation and low computational complexity. The proposed method has comparable quality and low computation time compared to other tone mapping algorithms.

\section{PREVIOUS WORKS}

\subsection{Tone mapping operators}

All the tone mapping methods developed for last years can be divided into two groups: global methods and local methods.

The main idea of global TMO (also known as spatially invariant) is to use the same function to all image pixels. Examples of these functions can be a power function, a logarithm, a sigmoid, or a function that is image dependent. Global TMOs take good results for scenes with a dynamic range approximately appropriate to the dynamic range of the display device, or lower. However, for scenes where the dynamic range is larger than the dynamic range of a display device, the global TMOs will compress the dynamic range of the scene too much, which result in a loss of contrast and detail visibility. Global TMOs are computationally simple, preserve the intensity orders of the original scenes, thus avoiding halo artefacts, and can suitable for video processing.

Example of the global TMOs is Reinhard TMO (Reinhard, 2005), which used the zone system for mapping HDR world image into LDR ones. In the zone system, the photographer first selects the middle-grade key in the image and then selects the darkest and brightest points to compute the dynamic range. Reinhard and his colleagues work on automating this system by mapping first the whole image using a local averaging logarithmic operator. Then they implemented an automated dodging and burning algorithm that uses a circular Gaussian 
operator at multiple scales and convolves it with the entire image to correct the bright and dark regions of the image. Shan et al. (Shan, 2009) presented a TMO which performs local adjustments across the entire HDR image on small windows which are overlapped. The linear adjustment is applied locally by each window, which preserves the radiance values monotonicity. A global optimization is applied to each overlapped window to satisfy the local constraints defined on them. For efficient reduction of high contrast and for preserving details, local constraints are used as a guidance. This method effectively reduces the global contrast and preserves details. Drago TMO (Drago, 2003) proposed the adaptive logarithmic TMO for compressing the luminance values by adaptively varying the logarithmic bases. They used contrast enhancement to improve the contrast of dark areas in the image. Kim et al. (Kim, 2008) presented a tone reduction algorithm based on a new $\mathrm{k}$ factor and highlight factor of compression.

The main idea of the local TMOs (also known as a spatial variant) is to use different functions for different spatial pixel positions. Local tone mapping methods can improve local contrast, and make the compressed image more detailed.

The group of local TMOs includes Ashikmin (Ashikhmin, 2002), which used the ratio of Gaussian filtered images to get the texture information. Fattal and his colleague (Fattal, 2002) developed a gradient-based TMO by compressing the gradient of the image luminance component and then constructing the LDR image by solving a Poisson equation on the compressed gradient image. Fairchild and Johnson (Fairchild, 2004) applied an image colour appearance model (called Image Color Appearance Model, iCAM) to chromatics. However, the color space transformation caused colour saturation loss. Kuang et al. (Kuang, 2007) designed an algorithm named iCAM06 based on the colour appearance model, which gives the perceptual attributes of each pixel, such as lightness, chromaticity, hue, contrast, and sharpness. It includes an inverse model that considers viewing conditions to generate the result. However, it also reduced colour saturation. Krawczyk et al. (Krawczyk, 2006) first segmented an HDR image and then applied different tone reproduction curves to the segments to achieve spatially variant HDR compression. Lischinski et al. (Lischinski, 2006) presented an interactive method to adjust the tonal values and other visual parameters locally. In their method, the user has a set of brushes to impose constraints on the image. Influence functions are computed to confine the modifications of the tonal value in image space. $\mathrm{Li}$ et al. $(\mathrm{Li}, 2005)$ presented a tone mapping technique, which relies on statistical and spatial information. In this technique, the image is initially divided into two layers i.e. base layer and detail layer. The base layer shows the smooth details and the detail layer represents the fine details. The statistically-based histogram adjustment is applied to the base layer. To obtain the detail layer, they use an adaptive spatial filter based on the mapping function of the base layer. The detailed layer after the enhancement is merged with the base layer. The tone-reduced image is obtained by applying the gain map on the detail-enhanced image. Durand and Dorsey TMO (Durand, 2002) employed the same technique, but the base layer is derived by the bilateral filter (Tomasi, 1998) to minimize of artefacts (halo-effects) around edges of objects on the image.

\subsection{Windowing operators}

The Windowing procedure is intended for visualization of HDR medical images. It maps the structural details within the intensity interval of interest at the dynamic range of regular displays. Such intervals of interest vary for different imaging modality and body parts. These intervals can be defined using two parameters: window width, the range of the interval, to be denoted here as $W$ and the window center, the center of this interval, to be denoted as $C$. It follows that the tone-mapping algorithm maps the range of luminance values $l$ in range $c-W / 2 \leq \mathbb{I} \leq c+W / 2$ to the LDR range [0,255] using linear function. Linear mapping is the most straightforward windowing operator but may not be the optimal mapping function in terms of structure-preserving (Nikvand, 2014). The windowing function may also be expressed using a linear combination of a family of sine basis functions. Experiments in (Nikvand, 2014) confirm that the linear mapping function is not optimal in terms of the fidelity of structural information. In addition, they show that modifying the mapping function to obtain maximal structural fidelity measurement produces computed tomography (CT) medical images with higher contrast and more visible details.

\subsection{Combined scheme of windowing operators and tone mapping operators}

The work (Athar, 2015) compares two different schemes for data rate and high dynamic range compression of medical images. In this work linear and optimized sine functions were used as the windowing operators.

In the first scheme, the LDR image is initially obtained by applying windowing to the HDR DICOM image and then, 8-bit JPEG2000 compression is applied to this LDR image to obtain the compressed LDR image. This scheme was called "Windowing-Compression" (WC). The compressed LDR image can then be transmitted to the end users. The benefit of this scheme is to maximally reduce the transmission bandwidth, but it suffers from two drawbacks: lossy image compression is being applied to an already altered image (as a result of windowing); since the end users receive an LDR image, further windowing is not possible and other body parts, that require different windows, cannot be retrieved. This can lead to retransmission requests and the requirement to store the original uncompressed HDR images at the source, which takes more storage space.

In the second scheme, image compression of the original HDR DICOM image is done first by using 16-bit JPEG2000 compression. This results in a compressed HDR image transmitted to the remote user. At the user side, the compressed HDR image is decompressed and windowing is applied to obtain an LDR image. This scheme was called "CompressionWindowing" (CW). The apparent advantages of this approach are: different types of windows can be applied at the user end, and thus different body parts can be viewed without retransmission of the images; compressed HDR images, instead of the original HDR images, can be stored at the source which leads to reduced storage requirement. The drawbacks are: more bandwidth may be required to transmit the image; typical browsers may not be able to decode and show images compressed at 16 bits, and thus dedicated software may need to be installed at the user end.

\section{TONE MAPPING TECHNIQUE BASED ON THE PROBABILISTIC GAMMA-NORMAL MODEL}

Tone-mapping of HDR DICOM images involves transforming the HDR DICOM image to an LDR medical image that can be presented on a standard display device. The complete tonemapping scheme is shown in Figure 1. First, we use the 
windowing operator based on a structural fidelity measure for optimal visualization of the input HDR DICOM image. Then, we transform the windowed image to the logarithm domain and share it on base and detail layers with the help of the probabilistic normal-gamma model. Base and detail layers are used to make the tone map with help the adaptive tone mapping operator. Finally, the tone mapping result is the LDR medical image.

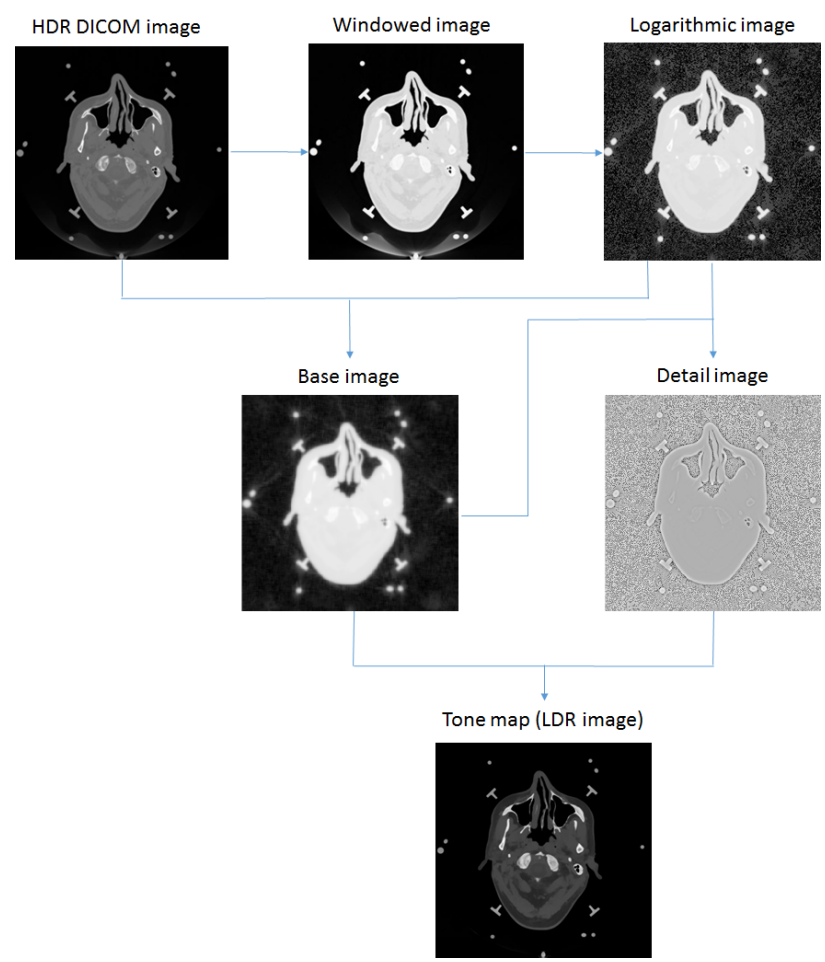

Figure 1. The complete tone-mapping scheme

Let's consider this scheme in more detail.

\subsection{Windowed image}

Let $X^{g}$ is the original HDR DICOM image. In the paper (Nikvand, 2014) one of the windowing operators $f\left(x^{g}\right)$ uses functions spanned by an appropriate family of sine functions $\phi_{k}\left(x^{g}\right) \quad(k=0,1,2, \ldots, n$, where $n$ is an order of approximation of $\left.f\left(x^{g}\right)\right)$ for receiving the windowed image

$$
\begin{aligned}
& f\left(x^{g}\right)=\sum_{k=0}^{n} c_{k} \phi_{k}\left(x^{g}\right), \\
& \phi_{k}\left(x^{g}\right)=\sin \left(\frac{k \pi\left(x^{g}-\mathrm{min}\left(x^{g}\right)\right)}{W}\right),
\end{aligned}
$$

for $\min \left(x^{\mathrm{g}}\right) \leq x^{\mathrm{g}} \leq \max \left(x^{\mathrm{g}}\right)$,

where $W=$ difference between maximal and minimal values intensity of input HDR DICOM image.

As a special case, when $n=3$, we have

$$
\begin{aligned}
f\left(x^{8}\right)=\frac{x^{8}-\min \left(x^{8}\right)}{W} & +c_{1} \sin \left(\frac{\pi\left(x^{8}-\min \left(x^{2}\right)\right)}{W}\right)+ \\
& +c_{2} \sin \left(\frac{2 \pi\left(x^{8}-\min \left(x^{2}\right)\right)}{W}\right)
\end{aligned}
$$

Constraints on the solutions of $c_{1}$ and $c_{2}$ :

$$
\left\{\begin{array}{l}
c_{1}+2 c_{2} \geq-\frac{1}{\pi} \\
-c_{1}+2 c_{2} \geq-\frac{1}{\pi} \\
\frac{c_{1}{ }^{2}}{16 c_{2}}+2 c_{2} \geq \frac{1}{\pi}
\end{array}\right.
$$

Then, the windowed image is applied to the logarithmic domain

$$
L=\log _{2}\left(f\left(x^{3}\right)\right)
$$

After the logarithm luminance channel is obtained, we can to decompose it into two layers: the base layer and the detail layer.

\subsection{Base and detail layers}

As mentioned earlier, we use the technique, which splits the image into two layers i.e. base layer and detail layer. The Bayesian approach described in (Gracheva, 2015) is based on the special model of the Markov field, called normal-gamma model (Krasotkina, 2010), which makes it possible to obtain the base layer. The base layer can be found by the structuretransferring technique similar to $\mathrm{He}$ et al. (He, 2013). The resulting image $X=\left(x_{t}, \mathbf{t} \in T\right)$ is obtained from the input HDR DICOM image $X^{g}=\left(x_{x}^{g}, \mathbf{t} \in T\right)$

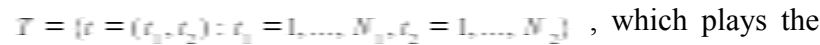
role of "guided" image and the logarithm domain image $Y=\left(y_{t}, \mathrm{t} \in T\right)$, which plays the role of the analyzed image. It is easy to see that the maximum a posteriori probability (MAP) estimate leads to the minimization of the following goal function.

$$
\begin{array}{r}
J(X, \Lambda \mid Y, \boldsymbol{\lambda}, \boldsymbol{\mu})=\sum_{\mathbf{t} \in T}\left(y_{t}-x_{t}\right)^{2}+ \\
+\sum_{\boldsymbol{t}^{\prime}, \boldsymbol{t}^{n} \in V}\left\{\frac{1}{\lambda_{t^{\prime}}}\left[\left(x_{t^{\prime}}-x_{t}\right)^{2}+\boldsymbol{\lambda} / \boldsymbol{\mu}\right]+\right. \\
\left.+\left(1+\frac{1}{\mu}\right) \ln \boldsymbol{\lambda}_{t}\right\} .
\end{array}
$$

Illustration of this structure-transferring scheme is in Figure 2. 


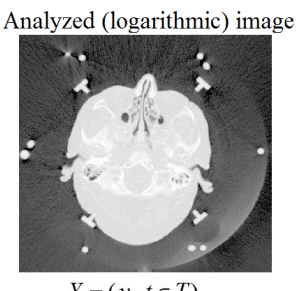

$Y=\left(y_{t}, t \in T\right)$

Guided (HDR DICOM) image

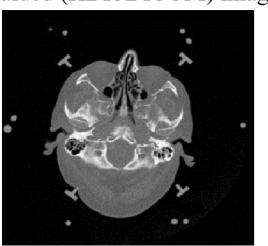

$X^{g}=\left(x_{t}^{g}, t \in T\right)$

Figure 2. Illustration of the structure-transferring scheme

Then the field of coefficients is fixed, MAP estimation of $X$ can be obtained as a solution of the following simple quadratic optimization task:

$$
\begin{aligned}
& \dot{X}=\arg \min J(X \mid \Lambda, Y, \boldsymbol{\lambda}, \not l)=
\end{aligned}
$$

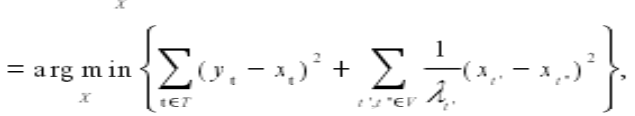

which can be solved by the extremely fast procedure on the basis of tree-serial dynamic programming (Mottl, 1998).

Then $X=\left(x_{t}, \mathrm{t} \in T\right)$ is fixed $X=X^{g}$, criterion (3) gives the following equation for optimal $\Lambda$ with fixed structural parameters $\lambda$ and $\mu$ :

$$
\hat{\lambda}_{\mathrm{r}^{\prime}}\left(X^{5}, \lambda, \mu\right)=\lambda \frac{(1 / \lambda)\left(x_{\mathrm{r}}^{5}-x_{\mathrm{r}}^{5}\right)^{2}+1 /, L}{1+1 /, \mu},\left(E^{2}, E^{\prime \prime}\right) \in V,
$$

where $\quad V=$ the lattice neighbourhood graph of the image elements

$\lambda=$ the smoothing degree of the result image

$\mu=$ the degree of bonds breaking near objects edges

Thus, the base layer stores information about the objects edges in the original HDR DICOM image, which further allows them to be taken into account when compressing the dynamic range.

Detail layer can be defined from the base layer and logarithm domain by the equation:

$$
D=L-B
$$

Decomposition into two layers is used for contrast reduction. A base layer $\mathrm{B}$ is computed by blurring a luminance image using a probabilistic normal-gamma model and a detail layer $\mathrm{D}$ is obtained by subtraction of base layer from the logarithm image. Further, the base layer is compressed by a tone-curve and added back to the detail layer thus reducing the dynamic range to a displayable level. The underlying assumption is that the detail layer will be predominantly low dynamic range while the base layer is HDR.

\subsection{LDR image}

We will employ a simplified version of Durand TMO (Durand, 2002). First of all, we apply an offset and a scale to the base layer:

$$
B^{\prime}=(B-\max (B)) \frac{d R}{\max (B)-\min (B)}
$$

The offset should provide the maximum intensity of the base equal to 1 since the values are in the log domain. The scale $d R$ is set so that the output base has stops of dynamic range.

Then we reconstruct the $\log$ intensity:

$$
T=2^{\left(B^{\prime}+D\right)}
$$

The result of the tone mapping transformation will be an LDR image.

\section{EXPERIMENTAL RESULTS}

The proposed algorithm and the current traditional tone mapping methods are tested in MATLAB (2015a) on the PC platform of Intel Core I5-2450M processor $(2.5 \mathrm{GHz}, 4 \mathrm{G}$ caches). The experimental dataset is chosen from Medical Image Samples website which provides HDR source images (http://www.barre.nom.fr/medical/samples/).

We will use three standard criteria to estimate the quality of the resulting images (see Table 1, Figure 3), criteria based on the neural networks (see Table 2, Figure 4) and computation time (Figure 5), received by the proposed method, and compare them to the results of other methods.

\subsection{Standard criteria}

4.1.1 The modified form of the peak signal-noise ratio (MPSNR): The quality measurement will be enhanced by using the MPSNR value. To measure the quality of the original image and reconstructed image, PSNR is used. PSNR is generally used for normal RGB images, but for the HDR images MPSNR is defined which will evaluate the quality of the original image and tone mapped image. MPSNR is used for the measurement of quality of reconstruction. It is described in the unit of a logarithmic decibel. If the value of MPSNR is high, means the reconstruction is of good quality. MPSNR can be defined by the equation (Yip, 2005)

$$
M P S N R=10 * \log _{10}\left(\frac{I * 255^{2}}{M S E}\right) \text {, }
$$

where $\quad I=$ luminance channel of the original HDR image $M S E=$ Mean square error

4.1.2 Mean square error (MSE): MSE is the aggregate of squared error between the reconstructed and the original image. It can be defined as a risk function which is related to the expected value of quadratic loss (Lehmann, 1998). It can be defined by equation

$$
M S E=\left(\frac{1}{M N}\right) \sum_{i=1}^{M} \sum_{j=1}^{N}[H D R(i, j)-\operatorname{LDR}(i, j)]
$$


where $\operatorname{HDR}(i, j)=$ original HDR DICOM image

$\operatorname{LDR}(i, j)=$ resulting LDR image

$M, N=$ dimensions

If the value of MSE is less, then mean error is also less.

4.1.3 Mean absolute error (MAE): MAE estimates how close the reconstructed image to the original image. It is the average of absolute errors (Willmott, 2005). It is defined by equation

$$
M A E=\frac{1}{n} \sum_{i=1}^{n}\left|e_{i}\right|
$$

where $\left|e_{i}\right|=\left|l d r_{i}-h d r_{i}\right|=$ absolute difference between reconstructed image $l d r_{i}$ and original image $h d r$

\begin{tabular}{|c|c|c|c|c|}
\hline \multirow[t]{2}{*}{ Method } & \multirow[t]{2}{*}{ Assessment } & \multicolumn{3}{|c|}{ Image } \\
\hline & & $\begin{array}{l}\text { CR- } \\
\text { MONO } \\
1-10- \\
\text { chest.dc } \\
\text { m }\end{array}$ & $\begin{array}{l}\text { CT- } \\
\text { MONO } \\
2-16- \\
\text { chest.dc } \\
\text { m }\end{array}$ & $\begin{array}{l}\text { OT- } \\
\text { MONO } \\
2-8- \\
\text { hip.dcm }\end{array}$ \\
\hline \multirow{4}{*}{$\begin{array}{l}\text { Durand } \\
\text { (Durand, } \\
\text { 2002) }\end{array}$} & PSNR & 10.086 & 2.968 & 23.796 \\
\hline & MSE & 10.201 & 0.505 & 2.397 \\
\hline & MAE & 0.541 & 0.704 & 0.582 \\
\hline & Time,s & 1 & 1.1 & 1.06 \\
\hline \multirow{4}{*}{$\begin{array}{l}\text { Drago } \\
\text { (Drago, } \\
2003 \text { ) }\end{array}$} & PSNR & 10.03 & 6.159 & 23.8 \\
\hline & MSE & 10.069 & 0.242 & 2.399 \\
\hline & MAE & 0.401 & 0.468 & 0.449 \\
\hline & Time,s & 0.837 & 0.756 & 0.694 \\
\hline \multirow{4}{*}{$\begin{array}{l}\text { Rainhard } \\
\text { (Rainhard, } \\
\text { 2005) }\end{array}$} & PSNR & 10.04 & 6.93 & 23.79 \\
\hline & MSE & 10.1 & 0.203 & 2.393 \\
\hline & MAE & 0.578 & 0.441 & 0.59 \\
\hline & Time,s & 1.49 & 1.09 & 1.04 \\
\hline \multirow{4}{*}{$\begin{array}{l}\text { Fattal } \\
\text { (Fattal, } \\
2002 \text { ) }\end{array}$} & PSNR & 10.031 & 6.455 & 23.818 \\
\hline & MSE & 10.072 & 0.226 & 2.409 \\
\hline & MAE & 0.275 & 0.472 & 0.335 \\
\hline & Time,s & 7.444 & 18.705 & 5.187 \\
\hline \multirow{4}{*}{$\begin{array}{l}\text { Qi Shan } \\
\text { (Shan, } \\
\text { 2009) }\end{array}$} & PSNR & 10.1 & 4.495 & 23.765 \\
\hline & MSE & 10.209 & 0.355 & 2.379 \\
\hline & MAE & 0.373 & 0.57 & 0.463 \\
\hline & Time,s & 26.316 & 49.438 & 50.062 \\
\hline \multirow{4}{*}{$\begin{array}{l}\text { Fast } \\
\text { guided } \\
\text { filter (He, } \\
2013)\end{array}$} & PSNR & 10.072 & 5.546 & 23.825 \\
\hline & MSE & 10.169 & 0.438 & 2.385 \\
\hline & MAE & 0.538 & 0.64 & 0.527 \\
\hline & Time,s & 0.621 & 1.25 & 1.189 \\
\hline \multirow{4}{*}{$\begin{array}{l}\text { Ashikhmi } \\
\mathrm{n} \\
\text { (Ashikhmi } \\
\mathrm{n}, 2002)\end{array}$} & PSNR & 10.015 & 8.393 & 23.812 \\
\hline & MSE & 10.034 & 0.145 & 2.406 \\
\hline & MAE & 0.304 & 0.34 & 0.318 \\
\hline & Time,s & 1.73 & 1.728 & 1.84 \\
\hline \multirow{4}{*}{$\begin{array}{l}\text { Banterle } \\
\text { (Banterle, } \\
\text { 2011) }\end{array}$} & PSNR & 10.05 & 6.159 & 23.785 \\
\hline & MSE & 10.115 & 0.242 & 2.4 \\
\hline & MAE & 0.4 & 0.468 & 0.544 \\
\hline & Time,s & 67.914 & 86 & 84.47 \\
\hline \multirow{4}{*}{$\begin{array}{l}\text { Krawczyk } \\
\text { (Krawczy } \\
\text { k, 2006) }\end{array}$} & PSNR & 9.977 & 9.184 & 23.786 \\
\hline & MSE & 9.946 & 0.121 & 2.391 \\
\hline & MAE & 0.224 & 0.3 & 0.489 \\
\hline & Time,s & 4.171 & 3.957 & 2.768 \\
\hline \multirow{3}{*}{$\begin{array}{l}\text { Lischinski } \\
\text { (Lischinsk } \\
\text { i, 2006) }\end{array}$} & PSNR & 10.002 & 6.879 & 23.796 \\
\hline & MSE & 10.004 & 0.205 & 2.397 \\
\hline & MAE & 0.347 & 0.413 & 0.414 \\
\hline
\end{tabular}

\begin{tabular}{|c|c|c|c|c|}
\hline & Time,s & 6.9 & 7.67 & 5 \\
\hline \multirow{4}{*}{$\begin{array}{ll}\mathrm{Li} & (\mathrm{Li}, \\
2005)\end{array}$} & PSNR & 9.98 & 8.057 & 23.77 \\
\hline & MSE & 9.955 & 0.156 & 2.383 \\
\hline & MAE & 0.227 & 0.36 & 0.369 \\
\hline & Time,s & 1.57 & 4.785 & 3.415 \\
\hline \multirow{4}{*}{$\begin{array}{l}\text { Tumburri } \\
\text { no } \\
\text { (Tamburri } \\
\text { no, 2008) }\end{array}$} & PSNR & 9.732 & 8.33 & 23.766 \\
\hline & MSE & 9.402 & 0.147 & 2.38 \\
\hline & MAE & 0.076 & 0.336 & 0.408 \\
\hline & Time,s & 0.684 & 1.9 & 1.842 \\
\hline \multirow{4}{*}{$\begin{array}{l}\text { Kuang } \\
\text { (Kuang, } \\
\text { 2007) }\end{array}$} & PSNR & 9.978 & 10.17 & 23.797 \\
\hline & MSE & 9.95 & 0.096 & 2.397 \\
\hline & MAE & 0.259 & 0.283 & 0.41 \\
\hline & Time,s & 7.1 & 5.3 & 5.636 \\
\hline \multirow{4}{*}{$\begin{array}{l}\text { Kim } \\
\text { (Kim, } \\
2008)\end{array}$} & PSNR & 10.01 & 6.205 & 23.787 \\
\hline & MSE & 10.022 & 0.24 & 2.393 \\
\hline & MAE & 0.355 & 0.47 & 0.515 \\
\hline & Time,s & 0.715 & 0.88 & 0.729 \\
\hline \multirow{4}{*}{$\begin{array}{l}\text { Mertens } \\
\text { (Mertens, } \\
2007)\end{array}$} & PSNR & 10.016 & 2.813 & 23.803 \\
\hline & MSE & 10.027 & 0.523 & 2.401 \\
\hline & MAE & 0.598 & 0.428 & 0.509 \\
\hline & Time,s & 5.81 & 5.923 & 5.276 \\
\hline \multirow{4}{*}{$\begin{array}{l}\text { Bruce } \\
\text { (Bruce, } \\
2013 \text { ) }\end{array}$} & PSNR & 10.104 & 3.614 & 23.806 \\
\hline & MSE & 10.243 & 0.435 & 2.402 \\
\hline & MAE & 0.6 & 0.662 & 0.59 \\
\hline & Time,s & 60.47 & 114.267 & 97 \\
\hline \multirow{4}{*}{$\begin{array}{l}\text { Raman } \\
\text { (Raman, } \\
\text { 2009) }\end{array}$} & PSNR & 10.106 & 2.255 & 23.788 \\
\hline & MSE & 10.248 & 0.6 & 2.392 \\
\hline & MAE & 0.623 & 0.776 & 0.695 \\
\hline & Time,s & 2.9 & 5 & 4.93 \\
\hline \multirow{4}{*}{$\begin{array}{l}\text { Our } \\
\text { method }\end{array}$} & PSNR & 10.107 & 10.28 & 23.773 \\
\hline & MSE & 9.2 & 0.084 & 2.4 \\
\hline & MAE & 0.15 & 0.35 & 0.273 \\
\hline & Time,s & 0.526 & 0.694 & 0.703 \\
\hline
\end{tabular}

Table 1. Comparison results of the proposed method and the current methods on the basis of PNSR, MSE and MAE estimations

Notice that maximal values are emphasized green colour, minimal values are emphasized red colour.

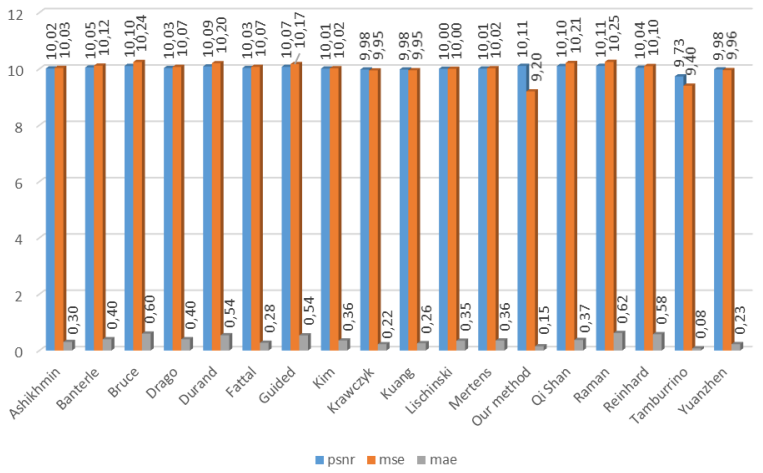

a) 


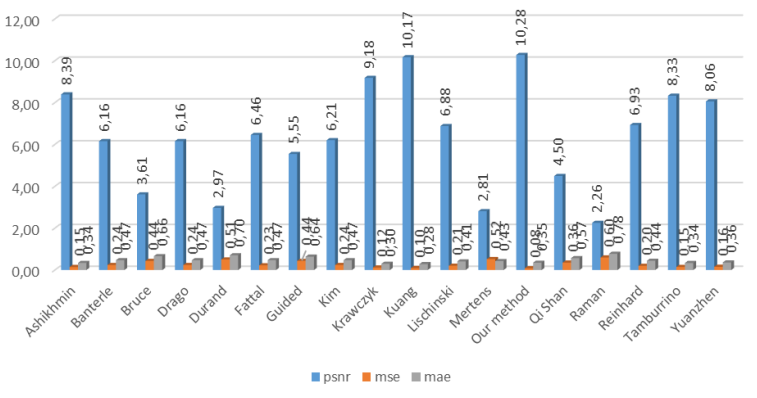

b)

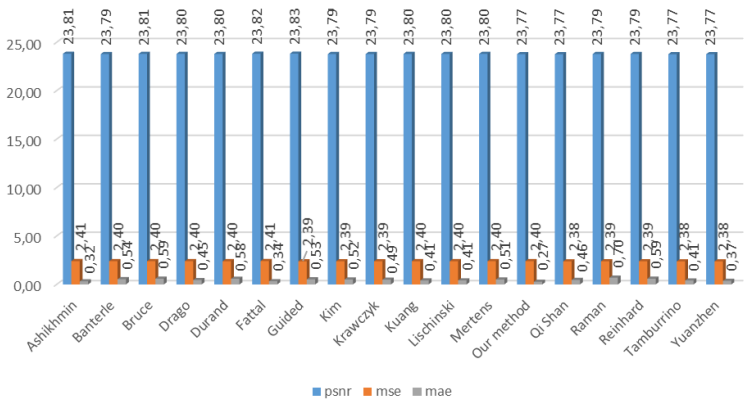

c)

Figure 3. Diagrams of quality comparison results (MPSNR, MSE, MAE) of the proposed method and the current methods for: a) CR-MONO1-10-chest.dem image; b) CT-MONO2-16chest.dcm image; c) OT-MONO2-8-hip.dcm image.

\subsection{Neural Image Assessment}

An application of machine learning methods to quality assessment of images has recently become a hot topic due to its usefulness in a wide variety of applications such as evaluating image capture pipelines, storage techniques, and sharing media. In this paper, we will use the Neural Image Assessment (NIMA) (Hossein, 2017) approach for images quality assessment (see Table 2, Fig.4). NIMA approach differs from others in that it predicts the distribution of human opinion scores using a convolutional neural network. NIMA architecture also has the advantage of being significantly simpler than other methods with comparable performance. NIMA stands on Inception-v2 (Szegedy, 2016), MobileNet (Howard, 2017) and ConvNet (Simonyan, 2014) image classifier architectures. Inception-v2 is based on Inception module (Ioffe, 2015) which allows for parallel use of convolution and pooling operations. Also, in the Inception-v2 architecture, traditional fully-connected layers are replaced by average pooling, which leads to a significant reduction in the number of parameters. MobileNet is an efficient deep $\mathrm{CNN}$, mainly designed for mobile vision applications. In this architecture, dense convolutional filters are replaced by separable depth filters. This simplification results in smaller and faster $\mathrm{CNN}$ models. ConvNet consists of 13 convolutional and 3 fully-connected layers. Small convolution filters of size $3 \times 3$ are used in the deep ConvNet architecture. Image quality assessment is done without the need for a "golden" reference image, consequently allowing for single-image, semantic- and perceptually-aware, no-reference quality assessment. NIMA's goal is to predict the distribution of ratings for a given image. Ground truth distribution of human ratings of a given image can be expressed as an empirical probability mass function $\mathrm{p}=\left[p_{s_{1}}, \ldots, p_{s_{N}}\right]$ with $s_{1} \leq s_{i} \leq s_{N}$, where $s_{i}$ denotes the $\mathrm{i}^{\text {th }}$ score bucket, and $N$ denotes the total number of score buckets.
Given the distribution of ratings as $p$, the mean quality score is defined as $\mu=\sum_{i=1}^{N} s_{i} \times p_{s_{i}}$, and the standard deviation of the score is computed as $\sigma=\left(\sum_{i=1}^{N}\left(s_{i}-\mu\right)^{2} \times p_{s_{i}}\right)^{1 / 2}$.

\begin{tabular}{|c|c|c|c|c|}
\hline \multirow[t]{2}{*}{ Method } & \multirow[t]{2}{*}{ Assessment } & \multicolumn{3}{|c|}{ Image } \\
\hline & & $\begin{array}{c}\text { CR- } \\
\text { MONO } \\
1-10- \\
\text { chest.dc } \\
\text { m } \\
(\mu( \pm \sigma))\end{array}$ & $\begin{array}{c}\text { CT- } \\
\text { MONO } \\
2-16- \\
\text { chest.dc } \\
\text { m } \\
(\mu( \pm \sigma))\end{array}$ & $\begin{array}{c}\text { OT- } \\
\text { MONO } \\
2-8- \\
\text { hip.dcm } \\
(\mu( \pm \sigma))\end{array}$ \\
\hline \multirow{3}{*}{$\begin{array}{l}\text { Durand } \\
\text { (Durand, } \\
\text { 2002) }\end{array}$} & $\begin{array}{l}\text { NIMA } \\
\text { (MobileNet) }\end{array}$ & $\begin{array}{l}5.146 \\
(1.591)\end{array}$ & $\begin{array}{l}4.651 \\
(1.680)\end{array}$ & $\begin{array}{l}4.364 \\
(1.765)\end{array}$ \\
\hline & $\begin{array}{l}\text { NIMA } \\
\text { (Inception- } \\
\text { v2) }\end{array}$ & $\begin{array}{l}4.681 \\
(1.742)\end{array}$ & $\begin{array}{l}4.175 \\
(1.714)\end{array}$ & $\begin{array}{l}3.968 \\
(1.655)\end{array}$ \\
\hline & $\begin{array}{l}\text { NIMA } \\
\text { (ConvNet) }\end{array}$ & $\begin{array}{l}4.482 \\
(1.408)\end{array}$ & $\begin{array}{l}3.077 \\
(1.423)\end{array}$ & $\begin{array}{l}3.032 \\
(1.378)\end{array}$ \\
\hline \multirow{3}{*}{$\begin{array}{l}\text { Drago } \\
\text { (Drago, } \\
2003 \text { ) }\end{array}$} & $\begin{array}{l}\text { NIMA } \\
\text { (MobileNet) }\end{array}$ & $\begin{array}{l}4.861 \\
(1.635)\end{array}$ & $\begin{array}{l}4.530 \\
(1.691)\end{array}$ & $\begin{array}{l}4.314 \\
(1.799)\end{array}$ \\
\hline & $\begin{array}{l}\text { NIMA } \\
\text { (Inception- } \\
\text { v2) }\end{array}$ & $\begin{array}{l}4.257 \\
(1.688)\end{array}$ & $\begin{array}{l}3.897 \\
(1.655)\end{array}$ & $\begin{array}{l}3.919 \\
(1.661)\end{array}$ \\
\hline & $\begin{array}{l}\text { NIMA } \\
\text { (ConvNet) }\end{array}$ & $\begin{array}{l}4.130 \\
(1.412)\end{array}$ & $\begin{array}{l}3.027 \\
(1.424\end{array}$ & $\begin{array}{l}2.803 \\
(1.354)\end{array}$ \\
\hline \multirow{3}{*}{$\begin{array}{l}\text { Rainhard } \\
\text { (Rainhard, } \\
\text { 2005) }\end{array}$} & $\begin{array}{l}\text { NIMA } \\
\text { (MobileNet) }\end{array}$ & $\begin{array}{l}4.911 \\
(1.640)\end{array}$ & $\begin{array}{l}4.523 \\
(1.691) \\
\end{array}$ & $\begin{array}{l}4.379 \\
(1.794)\end{array}$ \\
\hline & $\begin{array}{l}\text { NIMA } \\
\text { (Inception- } \\
\text { v2) }\end{array}$ & $\begin{array}{l}4.486 \\
(1.711)\end{array}$ & $\begin{array}{l}3.879 \\
(1.649)\end{array}$ & $\begin{array}{l}3.924 \\
(1.652)\end{array}$ \\
\hline & $\begin{array}{l}\text { NIMA } \\
\text { (ConvNet) }\end{array}$ & $\begin{array}{l}4.577 \\
(1.444)\end{array}$ & $\begin{array}{l}3.013 \\
(1.398) \\
\end{array}$ & $\begin{array}{l}2.822 \\
(1.359) \\
\end{array}$ \\
\hline \multirow{3}{*}{$\begin{array}{l}\text { Fattal } \\
\text { (Fattal, } \\
2002)\end{array}$} & $\begin{array}{l}\text { NIMA } \\
\text { (MobileNet) }\end{array}$ & $\begin{array}{l}4.699 \\
(1.641) \\
\end{array}$ & $\begin{array}{l}4.348 \\
(1.700) \\
\end{array}$ & $\begin{array}{l}4.099 \\
(1.807) \\
\end{array}$ \\
\hline & $\begin{array}{l}\text { NIMA } \\
\text { (Inception- } \\
\text { v2) }\end{array}$ & $\begin{array}{l}3.827 \\
(1.635)\end{array}$ & $\begin{array}{l}3.746 \\
(1.645)\end{array}$ & $\begin{array}{l}3.911 \\
(1.683)\end{array}$ \\
\hline & $\begin{array}{l}\text { NIMA } \\
\text { (ConvNet) }\end{array}$ & $\begin{array}{l}3.222 \\
(1.423)\end{array}$ & $\begin{array}{l}3.114 \\
(1.441)\end{array}$ & $\begin{array}{l}2.863 \\
(1.421)\end{array}$ \\
\hline \multirow{3}{*}{$\begin{array}{l}\text { Qi Shan } \\
\text { (Shan, } \\
\text { 2009) }\end{array}$} & $\begin{array}{l}\text { NIMA } \\
\text { (MobileNet) }\end{array}$ & $\begin{array}{l}4.978 \\
(1.599) \\
\end{array}$ & $\begin{array}{l}4.463 \\
(1.674) \\
\end{array}$ & $\begin{array}{l}4.369 \\
(1.808) \\
\end{array}$ \\
\hline & $\begin{array}{l}\text { NIMA } \\
\text { (Inception- } \\
\text { v2) }\end{array}$ & $\begin{array}{l}4.639 \\
(1.729)\end{array}$ & $\begin{array}{l}3.920 \\
(1.669)\end{array}$ & $\begin{array}{l}3.928 \\
(1.650)\end{array}$ \\
\hline & $\begin{array}{l}\text { NIMA } \\
\text { (ConvNet) }\end{array}$ & $\begin{array}{l}3.910 \\
(1.426)\end{array}$ & $\begin{array}{l}3.545 \\
(1.647) \\
\end{array}$ & $\begin{array}{l}2.958 \\
(1.376) \\
\end{array}$ \\
\hline \multirow{3}{*}{$\begin{array}{l}\text { Fast } \\
\text { guided } \\
\text { filter (He, } \\
2013)\end{array}$} & $\begin{array}{l}\text { NIMA } \\
\text { (MobileNet) }\end{array}$ & $\begin{array}{l}5.295 \\
(1.592)\end{array}$ & $\begin{array}{l}4.821 \\
(1.678)\end{array}$ & $\begin{array}{l}4.385 \\
(1.772)\end{array}$ \\
\hline & $\begin{array}{l}\text { NIMA } \\
\text { (Inception- } \\
\text { v2) }\end{array}$ & $\begin{array}{l}5.216 \\
(1.827)\end{array}$ & $\begin{array}{l}4.279 \\
(1.720)\end{array}$ & $\begin{array}{l}3.975 \\
(1.657)\end{array}$ \\
\hline & $\begin{array}{l}\text { NIMA } \\
\text { (ConvNet) }\end{array}$ & $\begin{array}{l}5.465 \\
(1.5) \\
\end{array}$ & $\begin{array}{l}3.026 \\
(1.354) \\
\end{array}$ & $\begin{array}{l}3.166 \\
(1.421) \\
\end{array}$ \\
\hline \multirow{3}{*}{$\begin{array}{l}\text { Ashikhmi } \\
\text { n } \\
\text { (Ashikhmi } \\
\text { n, 2002) }\end{array}$} & $\begin{array}{l}\text { NIMA } \\
\text { (MobileNet) }\end{array}$ & $\begin{array}{l}4.931 \\
(1.619)\end{array}$ & $\begin{array}{l}4.525 \\
(1.696)\end{array}$ & $\begin{array}{l}4.355 \\
(1.817)\end{array}$ \\
\hline & $\begin{array}{l}\text { NIMA } \\
\text { (Inception- } \\
\text { v2) } \\
\end{array}$ & $\begin{array}{l}4.476 \\
(1.711)\end{array}$ & $\begin{array}{l}3.934 \\
(1.653)\end{array}$ & $\begin{array}{l}3.852 \\
(1.649)\end{array}$ \\
\hline & $\begin{array}{l}\text { NIMA } \\
\text { (ConvNet) }\end{array}$ & $\begin{array}{l}4.339 \\
(1.423) \\
\end{array}$ & $\begin{array}{l}2.817 \\
(1.277)\end{array}$ & $\begin{array}{l}2.796 \\
(1.368) \\
\end{array}$ \\
\hline $\begin{array}{l}\text { Banterle } \\
\text { (Banterle, }\end{array}$ & $\begin{array}{l}\text { NIMA } \\
\text { (MobileNet) }\end{array}$ & $\begin{array}{l}4.879 \\
(1.634) \\
\end{array}$ & $\begin{array}{l}4.531 \\
(1.691) \\
\end{array}$ & $\begin{array}{l}4.456 \\
(1.836) \\
\end{array}$ \\
\hline
\end{tabular}




\begin{tabular}{|c|c|c|c|c|}
\hline \multirow[t]{2}{*}{ 2011) } & $\begin{array}{l}\text { NIMA } \\
\text { (Inception-v2) }\end{array}$ & $\begin{array}{l}4.324 \\
(1.711)\end{array}$ & \begin{tabular}{|l}
3.897 \\
$(1.655)$
\end{tabular} & $\begin{array}{l}3.964 \\
(1.670)\end{array}$ \\
\hline & \begin{tabular}{|l} 
NIMA \\
(ConvNet)
\end{tabular} & $\begin{array}{l}4.061 \\
(1.393) \\
\end{array}$ & \begin{tabular}{|l|}
3.027 \\
$(1.424)$ \\
\end{tabular} & $\begin{array}{l}2.843 \\
(1.303) \\
\end{array}$ \\
\hline \multirow{3}{*}{$\begin{array}{l}\text { Krawczyk } \\
\text { (Krawczy } \\
\text { k, 2006) }\end{array}$} & $\begin{array}{l}\text { NIMA } \\
\text { (MobileNet) }\end{array}$ & $\begin{array}{l}4.829 \\
(1.629)\end{array}$ & $\begin{array}{l}4.479 \\
(1.719)\end{array}$ & $\begin{array}{l}4.395 \\
(1.798)\end{array}$ \\
\hline & $\begin{array}{l}\text { NIMA } \\
\text { (Inception- } \\
\text { v2) }\end{array}$ & $\begin{array}{l}4.394 \\
(1.696)\end{array}$ & $\begin{array}{l}3.811 \\
(1.642)\end{array}$ & $\begin{array}{l}3.954 \\
(1.651)\end{array}$ \\
\hline & $\begin{array}{l}\text { NIMA } \\
\text { (ConvNet) }\end{array}$ & $\begin{array}{l}3.949 \\
(1.423) \\
\end{array}$ & $\begin{array}{l}2.949 \\
(1.351)\end{array}$ & $\begin{array}{l}3.089 \\
(1.406)\end{array}$ \\
\hline \multirow{3}{*}{$\begin{array}{l}\text { Lischinski } \\
\text { (Lischinsk } \\
\text { i, 2006) }\end{array}$} & $\begin{array}{l}\text { NIMA } \\
\text { (MobileNet) }\end{array}$ & $\begin{array}{l}4.963 \\
(1.629)\end{array}$ & $\begin{array}{l}4.539 \\
(1.674)\end{array}$ & $\begin{array}{l}4.400 \\
(1.798)\end{array}$ \\
\hline & $\begin{array}{l}\text { NIMA } \\
\text { (Inception- } \\
\text { v2) }\end{array}$ & $\begin{array}{l}4.673 \\
(1.756)\end{array}$ & $\begin{array}{l}3.943 \\
(1.653)\end{array}$ & $\begin{array}{l}3.958 \\
(1.651)\end{array}$ \\
\hline & $\begin{array}{l}\text { NIMA } \\
\text { (ConvNet) }\end{array}$ & $\begin{array}{l}4.715 \\
(1.452)\end{array}$ & $\begin{array}{l}3.019 \\
(1.364)\end{array}$ & $\begin{array}{l}2.948 \\
(1.381)\end{array}$ \\
\hline \multirow[t]{3}{*}{$\begin{array}{l}\mathrm{Li} \\
2005)\end{array}$} & $\begin{array}{l}\text { NIMA } \\
\text { (MobileNet) }\end{array}$ & $\begin{array}{l}5.044 \\
(1.601) \\
\end{array}$ & $\begin{array}{l}4.690 \\
(1.658)\end{array}$ & $\begin{array}{l}4.469 \\
(1.805) \\
\end{array}$ \\
\hline & $\begin{array}{l}\text { NIMA } \\
\text { (Inception- } \\
\text { v2) }\end{array}$ & $\begin{array}{l}4.881 \\
(1.746)\end{array}$ & $\begin{array}{l}4.232 \\
(1.674)\end{array}$ & $\begin{array}{l}4.042 \\
(1.655)\end{array}$ \\
\hline & $\begin{array}{l}\text { NIMA } \\
\text { (ConvNet) }\end{array}$ & $\begin{array}{l}4.883 \\
(1.429) \\
\end{array}$ & $\begin{array}{l}3.082 \\
(1.333)\end{array}$ & $\begin{array}{l}3.329 \\
(1.427) \\
\end{array}$ \\
\hline \multirow{3}{*}{$\begin{array}{l}\text { Tumburri } \\
\text { no } \\
\text { (Tamburri } \\
\text { no, 2008) }\end{array}$} & $\begin{array}{l}\text { NIMA } \\
\text { (MobileNet) }\end{array}$ & $\begin{array}{l}4.736 \\
(1.628) \\
\end{array}$ & $\begin{array}{l}4.445 \\
(1.687) \\
\end{array}$ & $\begin{array}{l}4.306 \\
(1.804) \\
\end{array}$ \\
\hline & $\begin{array}{l}\text { NIMA } \\
\text { (Inception- } \\
\text { v2) }\end{array}$ & $\begin{array}{l}4.032 \\
(1.657)\end{array}$ & $\begin{array}{l}3.771 \\
(1.622)\end{array}$ & $\begin{array}{l}4.033 \\
(1.676)\end{array}$ \\
\hline & $\begin{array}{l}\text { NIMA } \\
\text { (ConvNet) }\end{array}$ & $\begin{array}{l}3.628 \\
(1.462) \\
\end{array}$ & $\begin{array}{l}2.591 \\
(1.269) \\
\end{array}$ & $\begin{array}{l}3.175 \\
(1.453) \\
\end{array}$ \\
\hline \multirow{3}{*}{$\begin{array}{l}\text { Kuang } \\
\text { (Kuang, } \\
2007 \text { ) }\end{array}$} & $\begin{array}{l}\text { NIMA } \\
\text { (MobileNet) }\end{array}$ & $\begin{array}{l}4.896 \\
(1.603)\end{array}$ & $\begin{array}{l}4.505 \\
(1.690)\end{array}$ & $\begin{array}{l}4.390 \\
(1.754)\end{array}$ \\
\hline & $\begin{array}{l}\text { NIMA } \\
\text { (Inception- } \\
\text { v2) } \\
\end{array}$ & $\begin{array}{l}4.316 \\
(1.672)\end{array}$ & $\begin{array}{l}3.897 \\
(1.642)\end{array}$ & $\begin{array}{l}3.885 \\
(1.647)\end{array}$ \\
\hline & $\begin{array}{l}\text { NIMA } \\
\text { (ConvNet) }\end{array}$ & $\begin{array}{l}3.914 \\
(1.42) \\
\end{array}$ & $\begin{array}{l}2.9 \\
(1.321) \\
\end{array}$ & $\begin{array}{l}2.861 \\
(1.324) \\
\end{array}$ \\
\hline \multirow{3}{*}{$\begin{array}{l}\text { Kim } \\
\text { (Kim, } \\
2008)\end{array}$} & $\begin{array}{l}\text { NIMA } \\
\text { (MobileNet) }\end{array}$ & $\begin{array}{l}4.776 \\
(1.627) \\
\end{array}$ & $\begin{array}{l}4.538 \\
(1.685) \\
\end{array}$ & $\begin{array}{l}4.377 \\
(1.800) \\
\end{array}$ \\
\hline & $\begin{array}{l}\text { NIMA } \\
\text { (Inception- } \\
\text { v2) }\end{array}$ & $\begin{array}{l}4.108 \\
(1.656)\end{array}$ & $\begin{array}{l}4.052 \\
(1.673)\end{array}$ & $\begin{array}{l}3.982 \\
(1.668)\end{array}$ \\
\hline & $\begin{array}{l}\text { NIMA } \\
\text { (ConvNet) }\end{array}$ & $\begin{array}{l}4.038 \\
(1.402)\end{array}$ & $\begin{array}{l}2.959 \\
(1.36)\end{array}$ & $\begin{array}{l}3.007 \\
(1.39)\end{array}$ \\
\hline \multirow{3}{*}{$\begin{array}{l}\text { Mertens } \\
\text { (Mertens, } \\
2007)\end{array}$} & $\begin{array}{l}\text { NIMA } \\
\text { (MobileNet) }\end{array}$ & $\begin{array}{l}4.835 \\
(1.611) \\
\end{array}$ & $\begin{array}{l}4.329 \\
(1.704)\end{array}$ & $\begin{array}{l}4.27 \\
(1.798) \\
\end{array}$ \\
\hline & $\begin{array}{l}\text { NIMA } \\
\text { (Inception- } \\
\text { v2) } \\
\end{array}$ & $\begin{array}{l}4.078 \\
(1.640)\end{array}$ & $\begin{array}{l}3.942 \\
(1.688)\end{array}$ & $\begin{array}{l}3.940 \\
(1.674)\end{array}$ \\
\hline & $\begin{array}{l}\text { NIMA } \\
\text { (ConvNet) }\end{array}$ & $\begin{array}{l}.658 \\
(1.459) \\
\end{array}$ & $\begin{array}{l}3.289 \\
(1.457) \\
\end{array}$ & $\begin{array}{l}2.807 \\
(1.386) \\
\end{array}$ \\
\hline \multirow{3}{*}{$\begin{array}{l}\text { Bruce } \\
\text { (Bruce, } \\
2013 \text { ) }\end{array}$} & $\begin{array}{l}\text { NIMA } \\
\text { (MobileNet) }\end{array}$ & $\begin{array}{l}4.998 \\
(1.609) \\
\end{array}$ & $\begin{array}{l}4.571 \\
(1.731) \\
\end{array}$ & $\begin{array}{l}4.437 \\
(1.823) \\
\end{array}$ \\
\hline & $\begin{array}{l}\text { NIMA } \\
\text { (Inception- } \\
\text { v2) }\end{array}$ & $\begin{array}{l}4.142 \\
(1.662)\end{array}$ & $\begin{array}{l}4.033 \\
(1.699)\end{array}$ & $\begin{array}{l}4.057 \\
(1.687)\end{array}$ \\
\hline & $\begin{array}{l}\text { NIMA } \\
\text { (ConvNet) }\end{array}$ & $\begin{array}{l}3.835 \\
(1.401) \\
\end{array}$ & $\begin{array}{l}3.091 \\
(1.404) \\
\end{array}$ & $\begin{array}{l}2.822 \\
(1.391) \\
\end{array}$ \\
\hline \multirow{2}{*}{$\begin{array}{l}\text { Raman } \\
\text { (Raman, } \\
\text { 2009) }\end{array}$} & $\begin{array}{l}\text { NIMA } \\
\text { (MobileNet) }\end{array}$ & $\begin{array}{l}4.753 \\
(1.618) \\
\end{array}$ & $\begin{array}{l}4.344 \\
(1.703) \\
\end{array}$ & $\begin{array}{l}4.039 \\
(1.844) \\
\end{array}$ \\
\hline & $\begin{array}{l}\text { NIMA } \\
\text { (Inception- } \\
\text { v2) }\end{array}$ & $\begin{array}{l}3.899 \\
(1.625)\end{array}$ & $\begin{array}{l}4.003 \\
(1.698)\end{array}$ & $\begin{array}{l}4.013 \\
(1.712)\end{array}$ \\
\hline
\end{tabular}

\begin{tabular}{|l|l|l|l|l|}
\hline & $\begin{array}{l}\text { NIMA } \\
\text { (ConvNet) }\end{array}$ & $\begin{array}{l}3.358 \\
(1.423)\end{array}$ & $\begin{array}{l}2.911 \\
(1.335)\end{array}$ & $\begin{array}{l}2.778 \\
(1.375)\end{array}$ \\
\hline \multirow{3}{*}{$\begin{array}{l}\text { Our } \\
\text { method }\end{array}$} & NIMA & 5.186 & 4.836 & 4.167 \\
& (MobileNet) & $(1.59)$ & $(1.675)$ & $(1.819)$ \\
\cline { 2 - 5 } & $\begin{array}{l}\text { NIMA } \\
\text { (Inception- }\end{array}$ & 5.287 & 4.529 & 3.940 \\
& $(1.828)$ & $(1.724)$ & $(1.671)$ \\
& v2) & & & \\
\cline { 2 - 5 } & $\begin{array}{l}\text { NIMA } \\
\text { (ConvNet) }\end{array}$ & 5.806 & 3.457 & $\begin{array}{l}2.455 \\
(1.496)\end{array}$ \\
\hline
\end{tabular}

Table 2. Comparison results of the proposed method and the current methods on the basis of the NIMA with quality score $\mu( \pm \sigma)$, where $\mu$ and $\sigma$ represent the mean and standard deviation of the score, respectively

Notice that maximal values are emphasized green colour, minimal values are emphasized red colour.

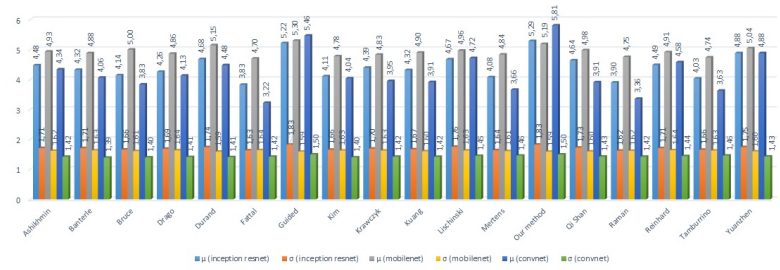

a)

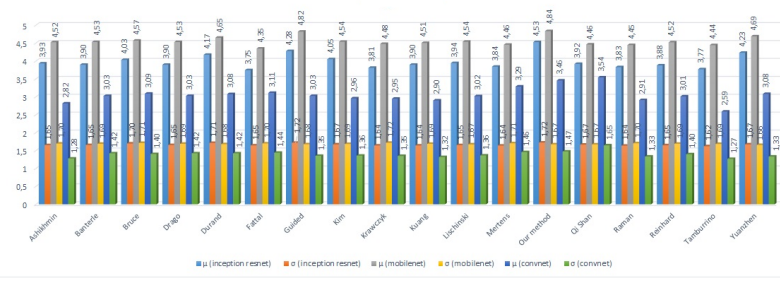

b)

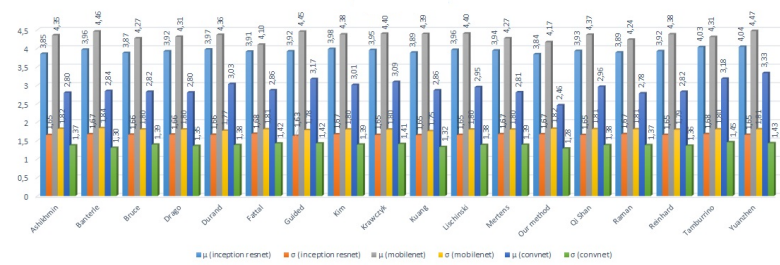

c)

Figure 4. Diagrams of quality comparison results (NIMA with quality score $\mu( \pm \sigma)$, where $\mu$ and $\sigma$ represent the mean and standard deviation of the score, respectively) of the proposed method and the current methods for: a) CR-MONO1-10chest.dcm image; b) CT-MONO2-16-chest.dem image; c) OTMONO2-8-hip.dem image.

\subsection{Computation time}

Figure 5 shows comparison results of fast TMO's and proposed method. 


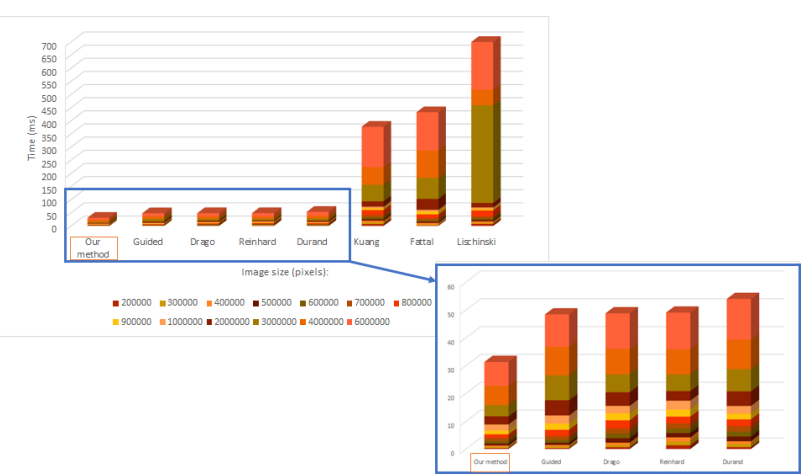

Figure 5. Time comparison results between the proposed method and other TMO algorithms

The comparison results of the proposed method by the processing quality are comparable with other TMOs, however, the computation time in all cases is lower than for the compared algorithms.

\section{CONCLUSIONS}

We presented the new tone mapping method based on the adaptive tone mapping operator and the probabilistic normalgamma model in this paper. First, we use the windowing operator that transforms the input HDR DICOM image range. Then we apply the filter based on the normal-gamma model to extract the base layer. Subtraction the base layer from the logarithm domain of the windowed image give us the detail layer. After that, the contrast reduced base layer and detail layer have been merged and a tone-reduced image is obtained. The quality of our tone mapping method results is comparable to other tone mapping algorithms. The comparison is done on the basis of three comparison metrics - MPSNR, MSE, MAE. To control the perceptual quality of images we use automatic images quality assessment NIMA approach. NIMA approach differs from others in that it predicts the distribution of human opinion scores using a convolutional neural network. NIMA architecture also has the advantage of being significantly simpler than other methods with comparable performance. NIMA stands on Inception-v2, MobileNet, and ConvNet image classifier architectures. The proposed method has comparable quality to other 17-th tone mapping algorithms, considered in the experimental comparison. However, the computation time of our tone mapping method lower than the computation time of other tone mapping algorithms. It gives the chance to use the proposed tone mapping method for the solution of dynamic HDR medical imaging compression problem.

\section{ACKNOWLEDGEMENTS (OPTIONAL)}

This work is supported by the Russian Fund for Basic Research, grants 16-57-52042, 17-07-00993, 18-07-00942.

\section{REFERENCES}

Ashikhmin M. 2002. A tone mapping algorithm for high contrast images. In: Proceedings of the 13th Eurographics workshop on Rendering, pp. 145-156.

Athar S., Yeganeh H. and Wang Z., 2015. Data Rate and Dynamic Range Compression of Medical Images: Which One
Goes First? In: IEEE International Conference on Image Processing, Quebec City, Canada, Sep. 2015.

Banterle F., Artusi A., Debattista K., Chalmers A., 2011. Advanced high dynamic range imaging: theory and practice. In: CRC Press.

Bruce N. D. B., 2013. ExpoBlend: Information preserving exposure blending based on normalized log-domain entropy. In: Elsevier Computer \& Graphics. doi.org/10.1371/journal.pone.0077883

Drago F., Myszkowski K., Annen T., and Chiba N., 2003. Adaptive logarithmic mapping for displaying high contrast scenes. In: Comput. Graph. Forum, 22(3), pp. 419-426.

Durand F., Dorsey J., 2002. Fast bilateral filtering for the display of high-dynamic-range images. In: SIGGRAPH, pp. 257 $-266$.

Fairchild M. D., Johnson G. M., 2004. iCAM framework for image appearance, differences, and quality. In: Journal of Electronic Imaging, 13(1), pp. 126-138.

Fattal R., Lischinski D., and Werman M., 2002. Gradient domain high dynamic range compression. In: SIGGRAPH, pp. 249-256.

Gracheva, I., Kopylov, A., 2017. Image processing algorithms with structure transferring properties on the basis of the normalgamma model. In: Communications in Computer and Information Science, Springer, 661, pp.257-268.

Gracheva, I., Kopylov, A., Krasotkina, O., 2015. Fast global image denoising algorithm on the basis of the nonstationary normal-gamma statistical model. In: Communications in Computer and Information Science, Springer, 542, pp.71-82.

He K., Sun J., Tang X., 2013. Guided image filtering. In: IEEE Transactions on Pattern Analysis and Machine Intelligence, 35(6), pp. 1397-1409.

Hossein T., Peyman M., 2017. NIMA: Neural Image Assessment. In: Computer Vision and Pattern Recognition (cs.CV), arXiv preprint arXiv:1709.05424 [cs.CV].

Howard A. G., Zhu M., Chen B., Kalenichenko D., Wang W., Weyand T., Andreetto M., and Adam H., 2017. MobileNets: Efficient convolutional neural networks for mobile vision applications. arXiv preprint arXiv:1704.04861.

Hung A. H. et al., 2013. High dynamic range processing for magnetic resonance imaging. In: PloS one, 8(11).

Ioffe S. and Szegedy C., 2015. Batch normalization: Accelerating deep network training by reducing internal covariate shift. In: International Conference on Machine Learning, pp. 448-456.

Kim M. H., Kautz J., 2008. Consistent Tone Reproduction. In: CGIM '08 Proceedings of the Tenth IASTED International Conference on Computer Graphics and Imaging.

Krasotkina, O., Kopylov, A., Mottl, V., and Markov, M., 2010. Bayesian estimation of time-varying regression with changing time-volatility for detection of hidden events in non-stationary signals. In: Proceedings of the 7th IASTED International 
Conference on Signal Processing, Pattern Recognition and Applications (SPPRA 2010), pp. 8-15.

Krawczyk G., Myszkowski K., and Seidel H.-P., 2006. Computational model of lightness perception in high dynamic range imaging. In: IS\&T/SPIE's Human Vision and Electronic Imaging.

Kuang J., Johnson G. M., and Fairchild M. D., 2007. iCAM06: A refined image appearance model for HDR image rendering. In J. Vis. Commun. Image R., 18, pp. 406-414.

Lehmann E., Casella G., 1998. Theory of Point Estimation. In: Second Edition Springer Texts in Statistics. Design, 41(3), pp. 589

Li Y., Sharan L., Adelson E.H., 2005. Compressing and companding high dynamic range images with subband architectures. In: ACM Trans. Graph, 24(3), pp. 836-844.

Lischinski D., Farbman Z., Uyttendaele M., and Szeliski R., 2006. Interactive local adjustment of tonal values. In: SIGGRAPH, pp. 646-653.

Mertens T., Kautz J., Reeth F.V., 2007. Exposure Fusion. In: Proceedings of Pacific Graphics.

Mottl, V., Kopylov A., Blinov, A., Kostin A., 1998. Optimization techniques on pixel neighbourhood graphs for image processing. In: Graph-Based Representations in Pattern Recognition Computing, Supplement 12, Springer, Wien, pp. 135-145.

Nikvand N., Yeganeh H., Wang Z., 2014. Adaptive windowing for optimal visualization of medical images based on normalized information distance. In: IEEE International Conference on Acoustics, Speech, and Signal Processing (ICASSP), Italy 2014.

Raman S. and Chaudhuri S., 2009. Bilateral Filter Based Compositing for Variable Exposure Photography. In: Eurographics.

Reinhard E., Devlin K., 2005. Dynamic range reduction inspired by photoreceptor physiology. In: IEEE Transaction on Computer Graphics and Visualization.

Shan Q., Jia J., Brown M.S., 2009. Globally Optimized Linear Windowed Tone Mapping. In: IEEE Transactions on Visualization and Computer Graphics, 16, pp.663-675.

Simonyan K. and Zisserman A., 2014. Very deep convolutional networks for large-scale image recognition. arXiv preprint arXiv:1409.1556.

Skurowski P., Wicher K., 2018. High Dynamic Range in X-ray Imaging. In: International Conference on Information Technologies in Biomedicine. Springer, Cham, pp. 39-51.

Szegedy C., Vanhoucke V., Ioffe S., Shlens J., and Wojna Z., 2016. Rethinking the inception architecture for computer vision. In: Proceedings of the IEEE Conference on Computer Vision and Pattern Recognition, pp. 2818-2826.

Tamburrino D., Alleysson D., Meylan L., and Susstrunk S., 2008. Digital camera workflow for high dynamic range images using a model of retinal processing. In: IS\&T/SPIE Electronic
Imaging: Digital Photography IV, SPIE Proceedings.

Tomasi C. and Manduchi R., 1998. Bilateral Filtering for Grey and Colour Images. In: Proc. IEEE Int-l Computer Vision Conf.

Willmott C. J., 2005. Advantages of the mean absolute error (MAE) over the root mean square error (RMSE) in assessing average model performance. In: Climate Research. 30, pp. 7982.

Yip S.K., Au O.O., Ho C.W., Wong H.M., 2005. PI-preserve data hiding for halftone image. In: Intelligent Signal Processing and Communication Systems (ISPACS), 1, pp.125-128. 